\title{
Bilirubin, ferritin, D-dimers and erythrophages in the cerebrospinal fluid of patients with suspected subarachnoid haemorrhage but negative computed tomography scans
}

\author{
K B Page, S J Howell, C M L Smith, D J W Dabbs, R G Malia, N R Porter, K J Thickett, \\ G M Wilkinson
}

\begin{abstract}
Aim-To assess the diagnostic value of cerebrospinal fluid (CSF) spectrophotometry, cytology, ferritin, and D-dimer measurements in the investigation of suspected subarachnoid haemorrhage in patients with negative or equivocal computed tomography (CT) scans.
\end{abstract}

Methods-CSF specimens submitted for assessment of xanthochromia were examined for erythrophages using a cytospin preparation stained with Wright's stain, for ferritin using the Ciba-Corning Magic IRMA assay, Ddimers using the Dimertest 2 latex agglutination slide test, and for bilirubin by scanning spectrophotometry. The patients were divided into three groups for data analysis and the results compared with the existing methods, CT, and angiogram results. Final diagnoses were reviewed by a consultant neurologist.

Results-Thirty six patients were recruited. In those patients with confirmed subarachnoid haemorrhage CSF cytology had a low sensitivity and there were false negative results with both the $D$-dimer and ferritin assays. Eleven patients with a negative or equivocal CT scan underwent angiography, but only one aneurysm and no arterio-venous malformations or bleeding points were identified. In the patient with the aneurysm there was no laboratory evidence of subarachnoid haemorrhage. Six patients had CSF abnormalities detected by the special tests only and in none of these cases was subarachnoid haemorrhage confirmed. All results were normal in four out of five cases of traumatic tap.

Conclusions-This is a small study, but it shows that, depending on the timing of the lumbar puncture, false negative results can occur with both ferritin and D-dimer measurements. It suggests that neither of these tests adds significantly to the information provided by CT, visualisation of CSF, and spectrophotometry and confirms that, despite the use of spectrophotometry, D-dimer and ferritin assays in selecting patients for angiography, the proportion of patients with negative CT scans and colourless CSF with demonstrable vascular lesions remains low.

(F Clin Pathol 1994;47:986-989)
Early diagnosis and surgery for appropriate cases of subarachnoid haemorrhage is now generally accepted to reduce morbidity and mortality. Most cases present with sudden severe headache associated with nausea and vomiting, meningeal signs, or altered level of consciousness and can be confirmed by computed tomography (CT). There is a group of patients, however, in whom CT is negative or presentation atypical. ${ }^{12}$ Thus, early lumbar puncture with examination of cerebrospinal fluid (CSF) is indicated for all patients with a negative CT scan and any suspicion of subarachnoid haemorrhage.

The CSF findings in subarachnoid haemorrhage include the presence of fresh blood and xanthochromia, but bloodstained CSF can also occur as a result of trauma to the spinal vessels during insertion of the needle. Historically, this problem has been addressed by counting the red cells in a number of consecutive bottles or by centrifuging the specimen and examining the supernatant fluid for xanthochromia. More recently, D-dimer ${ }^{3}$ and ferritin ${ }^{4}$ assays have been applied in this situation and spectrophotometry has been used to detect minor degrees of xanthochromia. The present study is an attempt to assess whether these tests might be of use in detecting small haemorrhages not causing xanthochromia and to compare the abilities of these tests to distinguish subarachnoid haemorrhage from traumatic tap, and thus to help in the selection of patients for cerebral angiography.

\section{Methods}

This study was designed as a collaborative study between the departments of Neurology, Neuropathology, Microbiology, Clinical Chemistry, and Haematology at the Royal Hallamshire Hospital, Sheffield. The patients were admitted over six months under the care of a number of clinical teams. The criteria for inclusion in the study were performance of a CT scan (using a Picker 1200SX scanner) and submission of a CSF specimen of about 3 $\mathrm{ml}$ or more for assessment of xanthochromia. The specimens received in the laboratory were initially observed for the presence of blood and a cell count was performed using a modified Fuchs-Rosenthal counting chamber. A $0.5 \mathrm{ml}$ aliquot was removed for cytology and the remaining CSF was centrifuged at $1500 \times g$ for 10 minutes. The colour of the supernatant fluid was then noted and three further aliquots removed. The uncentrifuged 
Table 1 Cerebrospinal fluid findings in patients with confirmed subarachnoid haemorrhage and aneurysms demonstrated by angiography

\begin{tabular}{|c|c|c|c|c|c|c|c|}
\hline $\begin{array}{l}\text { Case } \\
\text { No }\end{array}$ & $\begin{array}{l}\text { Time since } \\
\text { event }\end{array}$ & $\begin{array}{l}\text { Indication for } \\
L P\end{array}$ & Supernatant & Bilirubin & $\begin{array}{l}\text { D-dimers } \\
(\mu g / l)\end{array}$ & $\begin{array}{l}\text { Ferritin } \\
(\mu g / l)\end{array}$ & Erythrophages \\
\hline $\begin{array}{l}1 \\
2 \\
3 \\
4 \\
5 \\
6 \\
7 \\
8 \\
9 \\
10 \\
11 \\
12\end{array}$ & $\begin{array}{l}1 \text { day } \\
3 \text { days } \\
6 \text { days } \\
7 \text { days } \\
9 \text { days } \\
11 \text { days } \\
12 \text { days } \\
4 \text { weeks } \\
4 \text { weeks } \\
5 \text { weeks } \\
6 \text { weeks } \\
8 \text { weeks }\end{array}$ & $\begin{array}{l}\text { Hydrocephalus } \\
\text { Infection } \\
\text { Hydrocephalus } \\
\text { Hydrocephalus } \\
\text { ? Infection } \\
\text { Hydrocephalus } \\
\text { Diagnostic } \\
\text { Hydrocephalus } \\
\text { ? Rebleed } \\
\text { ? Rebleed } \\
\text { Hydrocephalus } \\
\text { Infection }\end{array}$ & $\begin{array}{l}\text { Xanthochromia } \\
\text { Amber } \\
\text { Xanthochromia } \\
\text { Xanthochromia } \\
\text { Amber } \\
\text { Amber } \\
\text { Amber } \\
\text { Xanthochromia } \\
\text { Xanthochromia } \\
\text { Red } \\
\text { CC } \\
\text { CC }\end{array}$ & $\begin{array}{l}\text { Positive } \\
\text { Positive } \\
\text { Positive } \\
\text { Positive } \\
\text { Positive } \\
\text { Positive } \\
\text { Positive } \\
\text { Positive } \\
\text { Positive } \\
\text { Positive } \\
\text { Negative } \\
\text { Negative }\end{array}$ & $\begin{array}{r}4000 \\
1000 \\
500 \\
1000 \\
<250 \\
1000 \\
1000 \\
<250 \\
4000 \\
1000 \\
<250 \\
500\end{array}$ & $\begin{array}{r}7 \\
1838 \\
693 \\
103 \\
392 \\
1175 \\
3117 \\
154 \\
57 \\
4299 \\
60 \\
101\end{array}$ & $\begin{array}{l}\text { Negative } \\
\text { Negative } \\
\text { NS } \\
\text { EQ } \\
\text { Positive } \\
\text { NS } \\
\text { Negative } \\
\text { Positive } \\
\text { NS } \\
\text { NS } \\
\text { Positive } \\
\text { Positive }\end{array}$ \\
\hline
\end{tabular}

NS = not suitable; $\mathrm{EQ}=$ equivocal; $\mathrm{CC}=$ clear and colourless; $\mathrm{LP}=$ lumbar puncture. ${ }^{\star}$ Visible to the naked eye. Case 7 had a positive computed tomography scan which was initially misinterpreted as negative.

aliquot was used to make two cytospin preparations, which were fixed in methanol and stained with Wright's stain before being examined under the microscope for phagocytes containing red cell debris (erythrophages).

Bilirubin content was assessed by scanning spectrophotometry using a Hitachi model U2000 double beam spectrophotometer, scanning between 600 and $380 \mathrm{~nm}$. The characteristic broad peak with an absorption maximum at about $450 \mathrm{~nm}$ or a typical shoulder on a larger oxyhaemoglobin peak were taken as evidence of the presence of bilirubin and confirmed by viewing the first order derivative curve. Trace amounts of bilirubin in the presence of a large excess of oxyhaemoglobin were confirmed by integrating the first order curve between 503.5 and $505.5 \mathrm{~nm}$. The sensitivity of this method was about $0 \cdot 15 \mu \mathrm{mol} / 1$.

D-dimers were measured using a semiquantitative latex agglutination slide test (Dimertest 2, Agen Biomedical, Brisbane, Australia) incorporating a monoclonal antibody linked to latex particles to detect crosslinked fibrin degradation products and which has a sensitivity of $250 \mu \mathrm{g} / 1$. Ferritin measurements were made using the Ciba-Corning Magic immunoradiometric assay (CSF reference range 0-7 $\mu \mathrm{g} / \mathrm{l}$ ). Both immunoassays were validated for use with CSF before the study began.

Four-vessel cerebral angiography was performed on selected patients with a positive CT scan, xanthochromia, or a high index of clinical suspicion. The clinical features and final diagnosis in each case were reviewed by a consultant neurologist at the end of the study. The patients were divided into three groups for analysis of the data: those with blood visible in the subarachnoid space on the CT scan; those with negative CT scans who underwent cerebral angiography, and those with negative CT scans who did not proceed to angiography. The protocol was approved by the Royal Hallamshire Hospital Medical Research Ethical Committee.

\section{Results}

Thirty six patients were recruited but satisfactory cytospin preparations were obtained in 23 only. This was mainly because immediate processing to preserve the cellular architecture was not always possible outside normal laboratory hours. Cerebrospinal fluid findings for the three groups are shown in tables 1-3.

Most specimens from patients with confirmed subarachnoid haemorrhage (table 1) were taken for therapeutic (relief of hydrocephalus) rather than for diagnostic reasons (suspected recurrent haemorrhage or infection), and most patients had undergone surgery to repair an aneurysm. The negative findings in this group are useful in suggesting some of the limitations of the tests. Erythrophages were not detected in half of the cases where a suitable specimen was obtained. D-dimers were not detected in one specimen at nine days and the ferritin concentration was borderline in one specimen taken 16 hours after the onset of symptoms. Had the specimens been submitted for detection of subarachnoid haemorrhage, the diagnosis would

Table 2 Cerebrospinal fluid findings and final diagnoses in patients with negative computed tomography scans proceeding to angiography

\begin{tabular}{llllllll}
\hline $\begin{array}{l}\text { Case } \\
\text { No }\end{array}$ & $\begin{array}{l}\text { Time since } \\
\text { event }\end{array}$ & Supernatant & Bilirubin & $\begin{array}{l}\text { D-dimers } \\
(\mu g / l)\end{array}$ & $\begin{array}{l}\text { Ferritin } \\
(\mu g / l)\end{array}$ & Erythrophages & Final diagnosis \\
\hline 13 & 1 day & CC & Negative & $<250$ & 5 & NS & Cerebral infarct \\
14 & 1 day & CC & Negative & $<250$ & 10 & Negative & Old brainstem haemorrhage \\
15 & 1 day & CC (TT) & Negative & $<250$ & 6 & Negative & Internal carotid aneurysm \\
16 & 1 day & Xanthochromia & Positive & 500 & 16 & Negative & SAH \\
17 & 1 day & Xanthochromia & Positive & 250 & 4 & NS & SAH \\
18 & 2 days & Amber (TT) & Positive & $250+$ & 13 & NS & SAH \\
19 & 4 days & Amber & Positive & $<250$ & 14 & NS & SAH \\
20 & 7 days & CC (TT) & Negative & $<250$ & 3 & Negative & Undetermined \\
21 & 8 days & CC & Positive & $<250$ & 4 & NS & Tension headache \\
22 & 10 days & CC & Negative & 250 & 12 & Negative & Undetermined \\
23 & 2 weeks & CC & Negative & $<250$ & 3 & NS & Viral infection \\
\hline
\end{tabular}

CC = clear and colourless; TT = traumatic tap; NS = not suitable; SAH = subarachnoid haemorrhage. ${ }^{\star}$ Visible to the naked eye All angiograms were normal with the exception of that performed on case 15 which showed extensive atherosclerosis and a distal internal carotid aneurysm. Case 21 had an increased serum bilirubin. 
Table 3 Cerebrospinal fluid findings and final diagnoses in patients with negative computed tomography scans not proceeding to angiography

\begin{tabular}{|c|c|c|c|c|c|c|c|}
\hline $\begin{array}{l}\text { Case } \\
\text { No }\end{array}$ & $\begin{array}{l}\text { Time since } \\
\text { event/duration }\end{array}$ & Supernatant & Bilirubin & $\begin{array}{l}\text { D-dimers } \\
(\mu g / l)\end{array}$ & $\begin{array}{l}\text { Ferritin } \\
(\mu g / l)\end{array}$ & Erythrophages & Final diagnosis \\
\hline $\begin{array}{l}24 \\
25 \\
26 \\
27 \\
28 \\
29 \\
30 \\
31 \\
32 \\
33 \\
34 \\
35 \\
36\end{array}$ & $\begin{array}{l}1 \text { day } \\
1 \text { day } \\
2 \text { days } \\
3 \text { days } \\
4 \text { days } \\
7 \text { days } \\
7 \text { days } \\
7 \text { days } \\
8 \text { days } \\
2 \text { weeks } \\
2 \text { weeks } \\
2 \text { weeks } \\
\text { Intermittent } \\
\quad 1 \text { year }\end{array}$ & $\begin{array}{l}\text { CC }(T T) \\
\text { CC } \\
\text { CC } \\
\text { CC (TT) } \\
\text { CC } \\
\text { CC } \\
\text { CC } \\
\text { CC } \\
\text { CC } \\
\text { CC } \\
\text { CC } \\
\text { Xanthochromia } \\
\text { CC }\end{array}$ & $\begin{array}{l}\text { Negative } \\
\text { Negative } \\
\text { Positive } \\
\text { Negative } \\
\text { Positive } \\
\text { Negative } \\
\text { Negative } \\
\text { Negative } \\
\text { Positive } \\
\text { Negative } \\
\text { Negative } \\
\text { Positive } \\
\text { Negative }\end{array}$ & $\begin{array}{r}<250 \\
<250 \\
<250 \\
<250 \\
250 \\
<250 \\
<250 \\
<250 \\
<250 \\
<250 \\
<250 \\
<250 \\
<250\end{array}$ & $\begin{array}{r}5 \\
6 \\
3 \\
3 \\
6 \\
6 \\
3 \\
6 \\
14 \\
5 \\
6 \\
84 \\
3\end{array}$ & $\begin{array}{l}\text { Negative } \\
\text { NS } \\
\text { NS } \\
\text { NS } \\
\text { Negative } \\
\text { Negative } \\
\text { Negative } \\
\text { Negative } \\
\text { Negative } \\
\text { Negative } \\
\text { Negative } \\
\text { NS } \\
\text { Negative }\end{array}$ & $\begin{array}{l}\text { Migraine } \\
\text { Post-ictal headache } \\
\text { Coital cephalgia } \\
\text { Cervical spondylosis } \\
\text { Neurosarcoid } \\
\text { Migraine } \\
\text { Migraine } \\
\text { Hyponatraemia (diuretics) } \\
\text { Venous sinus thrombosis } \\
\text { Migraine } \\
\text { Tension headache } \\
\text { Cerebral haemorrhage } \\
\text { Neurosarcoid }\end{array}$ \\
\hline
\end{tabular}

$\mathrm{CC}=$ clear and colourless; TT = traumatic tap; NS = not suitable. ${ }^{\star}$ Case 32 had two 'blood patch' procedures (injection of blood into the extradural space to seal a cerebrospinal fluid leak following spinal analgesia) before the diagnostic lumbar puncture. $\star \star$ Visible to the naked eye.

have been apparent from visible xanthochromia in all cases less than one month old.

Eleven patients were reported to have normal CT scans but underwent cerebral angiography because of bloodstained, or xanthochromic CSF, or strong clinical suspicion of subarachnoid haemorrhage (table 2). Case 15 had an abnormal angiogram, with extensive atherosclerosis and a distal internal carotid aneurysm. Although this patient's CSF was bloodstained on two separate occasions, in each case there was a falling cell count in the three bottles with a colourless supernatant fluid after centrifugation, and all further tests on the CSF were negative. The diagnoses in the remaining cases were often tentative. Four patients were thought to have sustained a subarachnoid haemorrhage on the basis of a classic presentation; xanthochromic $\mathrm{CSF}$ and the $\mathrm{D}$-dimer and ferritin assays were each positive in three cases. The final diagnosis was undetermined in cases 20 and 22 . A trace of bilirubin was found in the specimen from case 21 who also had an increased serum bilirubin concentration.

The findings in patients not proceeding to angiography are shown in table 3 . One patient caused diagnostic confusion initially because of two previous "blood patch" procedures (injection of the patient's own blood into the extradural space) performed to treat a CSF leak following spinal analgesia.

Of the five suspected traumatic taps we examined, four were negative on all tests. The remaining specimen had an amber coloured supernatant fluid and seemed to contain a mixture of haemoglobin and bilirubin on spectroscopy. The D-dimer and ferritin assays were also positive in this specimen.

\section{Discussion}

Computed tomography fails to demonstrate blood in the subarachnoid space in a significant proportion of cases of subarachnoid haemorrhage, especially when the patient is orientated at presentation. ${ }^{1256}$ Further investigation of these patients is complicated by limited resources, the potential hazards of cerebral angiography, and the low prevalence of provable subarachnoid haemorrhage in this group. Any delay in diagnosis, however, may contribute to greater morbidity and mortality. ${ }^{1}$ Opinions vary as to the sensitivity of xanthochromia as a marker for subarachnoid haemorrhage $\mathrm{e}^{78}$ and it has been argued that the disagreement is due to variation in the method of direct visual inspection and the greater sensitivity of spectrophotometry. ${ }^{910}$ Not everyone accepts this explanation, however. ${ }^{11}$ This study was performed to compare the sensitivities of a spectrophotometric method for bilirubin with the D-dimer and ferritin assays initially described for use in cases of suspected traumatic tap. Our main question was whether absence of xanthochromia, as defined by visual inspection, or scanning spectrophotometry exclude subarachnoid haemorrhage. Vermeulen et $a l^{8}$ obviously thought so and the follow up study of Wijdicks et al, ${ }^{12}$ in which 71 patients with sudden onset of headache and no evidence of subarachnoid bleeding on CT or examination of CSF were followed for a mean of 3.3 years, would seem to support this view. The results of such studies, however, may be sensitive to local referral patterns and laboratory methods.

Some of the controversy about xanthochromia probably arises from the meaning assigned to the term. We believe that the term "xanthochromia" should be reserved for the yellow appearance of CSF observed under direct vision. Specimens containing clinically important amounts of free haemoglobin in addition to bilirubin generally look amber or red in colour and a report of amber coloured CSF was initially misinterpreted as excluding subarachnoid haemorrhage in at least one case during the present study. Scanning spectrophotometry has been used for nearly 20 years for the detection of small quantities of bilirubin in the presence of haemoglobin. ${ }^{13-16}$ However, when the haemoglobin concentration is very high, the detection of a small amount of bilirubin can be difficult and examination of the first order derivative of the absorption curve (derivative spectrophotometry) may be helpful. ${ }^{17}{ }^{18}$ An even more sensitive method which combines derivative spectrophotometry with formation of azobilirubin has been described recently, ${ }^{19}$ but our initial experiments did not confirm any 
advantage for specimens containing appreciable quantities of haemoglobin. Integration of the first order derivative curve between 503.5 and $505.5 \mathrm{~nm}$ was useful for a few specimens with very high haemoglobin concentrations because oxyhaemoglobin causes minimal interference between these wavelengths.

The sensitivity of our D-dimer assay (250 $\mu \mathrm{g} / \mathrm{l})$ was slightly inferior to that in the method used by Lang et $\mathrm{al}^{4}(200 \mu \mathrm{g} / \mathrm{l})$ in a study of the value of the test in traumatic tap. Borderline results, therefore, were reported as $250 \mu \mathrm{g} / 1$ and treated as positive.

The CSF ferritin concentration is increased in inflammatory and vascular disorders of the central nervous system (CNS) and in some cases of dementia, especially when associated with hydrocephalus. ${ }^{2021}$ In their study of ferritin measurements in traumatic tap Wick et $a l^{3}$ made a correction for the red cell count based on the addition of EDTA blood to clear CSF. We found this precaution to be unnecessary in practice when specimens were transported and centrifuged without delay.

Confusion can arise in individual cases, as illustrated by case 15 . This patient was referred from another hospital with a diagnosis of subarachnoid haemorrhage despite a negative CT scan and a falling red cell count in consecutive bottles of CSF. A second specimen also looked as if it was a traumatic tap and all tests on the CSF were negative. At angiography, however, extensive atherosclerosis and an aneurysm were detected but, unfortunately, the patient sustained a stroke during the procedure. Similar cases have been reported before ${ }^{22-24}$ and the aneurysms detected are thought either to be unrelated to the presenting headache or to have sustained a minor leak or sudden enlargement. If a minor leak was responsible for the symptoms in our patient, it was not detected by any of the tests used.

As will be apparent from tables 1 and 2, the timing of lumbar puncture affects the diagnostic values of the tests, making conclusions about sensitivities difficult. Both false negative ferritin results (cases 1 and 17) were obtained on specimens taken within 24 hours of the onset of headache. All false negative D-dimer results were on specimens taken at least four days after the event. The non-specific nature of ferritin measurements has been mentioned above and is a potential source of false positive results; however, cases 21 and 26 appeared to have false positive results by spectrophotometry. Case 21 had an increased serum bilirubin concentration, which was probably the cause of the trace of bilirubin detected in his CSF as the onset of his headache was probably gradual, with no signs of meningeal irritation and seemed to wax and wane in severity over the course of several days. In case 26 the presentation was typical of coital cephalgia and again there were no meningeal signs or nausea. Serum bilirubin concentrations were not measured in this patient and the reason for the trace of bilirubin detected in the CSF remains unknown.

In conclusion, we found no cases of sub- arachnoid haemorrhage with a demonstrable vascular lesion on angiography in the absence of visible xanthochromia. The small size of our study prevents any definitive conclusions regarding the use of these tests, but it shows that, depending on the timing of lumbar puncture, false negative results are possible with both $\mathrm{D}$-dimer and ferritin measurements and that these two tests do not provide clinically relevant additional diagnostic information to CT, visualisation of CSF, and spectrophotometry. Despite the use of spectrophotometry, D-dimer and ferritin measurements in the selection of patients for angiography, the proportion of patients with negative CT scans and colourless CSF with demonstrable vascular lesions remains low.

1 Chan BSH, Dorsch NWC. Delayed diagnosis in subarachnoid haemorrhage. Med $\mathcal{F}$ Aust 1991;154:509-11.

2 Johnston SRD, Hammond A, Griffiths L, Greenwood R, Clarke CRA. Subarachnoid haemorrhage-can we do better? $\mathcal{F} R$ Soc Med 1989;82:721-4.

3 Lang DT, Berberian LB, Lee S, Ault M. Rapid differentiation of subarachnoid hemorrhage from traumatic lumbar puncture using the D-dimer assay. Am $\mathcal{f}$ Clin Pathol 1990;93:403-5.

4 Wick M, Fink W, Pfister W, Einhaupl K, Huber M, FatehMoghadam A. Ferritin in cerebrospinal fluid differentiation between central nervous system haemorrhage and traumatic spinal puncture. $\mathcal{F}$ Clin Pathol 1988;41: 809-14.

5 Anonymous. Headaches and subarachnoid haemorrhage. [Editorial]. Lancet 1988:ii:80-2.

6 Adams HP, Kassell NF, Torner JC, Sahs AL. CT and clinical correlations in recent aneurysmal subarachnoid haemorrhage; a preliminary report of the cooperative aneurysm study. Neurology 1983;33:981-8.

7 MacDonald A, Mendelow AD. Xanthochromia revisited: a re-evaluation of lumbar puncture and CT-scanning in the diagnosis of subarachnoid haemorrhage. $\mathcal{f}$ Neurol Neurosurg Psychiatry 1988;51:342-4

8 Vermeulen M, Hasan D, Blijenberg BG, Hijdra A, Van Gijn J. Xanthochromia after subarachnoid haemorrhage needs no revisitation. $\mathcal{f}$ Neurol Neurosurg Psychiatry 1989;52:826-8.

9 Anonymous. Xanthochromia [Editorial]. Lancet 1989;ii: 658-9.

10 Mendelow AD, Cartlidge N. Xanthochromia in subarachnoid haemorrhage. $\mathcal{F}$ Neurol Neurosurg Psychiatry 1990; 53:270-1.

11 Beetham R. Spectrophotometric examination of CSF for xanthochromia. Lancet 1992;i:1492.

12 Wijdicks EFM, Kerkhoff H, Van Gijn J. Long-term followup of 71 patients with thunderclap headache mimicking subarachnoid haemorrhage. Lancet 1988;ii:68-9.

13 Kjellin KG, Soderstrom CE. Diagnostic significance of CSF spectrophotometry in cerebrovascular diseases. $\mathcal{f}$ Neurol Sci 1974;23:359-69.

14 Kjellin KG, Steiner L. Spectrophotometry of cerebrospinal fluid in subacute and chronic subdural haematomas. $\mathcal{F}$ Neurol Neurosurg Psychiatry 1974;37:1121-7.

15 Norrving B, Olsson J. The diagnostic value of spectrophotometric analysis of the cerebrospinal fluid in cerebra tometric analysis of the cerebrospinal fluid
hematomas. $\mathcal{F}$ Neurol Sci 1979;44:105-14.

16 Buruma OJS, Janson HLF, Den Bergh FAJTM, Bots GTHAM. Blood-stained cerebrospinal fluid: traumatic puncture or haemorrhage? $\mathcal{F}$ Neurol Neurosurg Psychiatry 1981;44:144-7.

17 Amazon K, Soloni F, Rywlin AM. Separation of bilirubin from haemoglobin by recording derivative spectrophotometry. Am f Clin Pathol 1981;75:519-23.

18 Stroes JW, Van Rijn HJM. Quantitative measurement of blood pigments in cerebrospinal fluid by derivative spectrophotometry. Ann Clin Biochem 1987;24:189-97.

19 Gimpel JA, Van Rijn HJM, Putters J. Reference interval for the bilirubin excess in cerebrospinal fluid by derivative spectrophotometry. $\mathcal{f}$ Clin Chem Clin Biochem 1989;
27:217-9.

20 Halgren R, Terent A, Wide L, Bergstrom K, Birgegard G. Cerebrospinal fluid ferritin in patients with cerebral infarction or bleeding. Acta Neurol Scand 1980;61 384-92.

21 Sindii CJM, Collet-Cassart D, Cambiaso CL, Masson PL Latesse EC. The clinical relevance of ferritin concentration in the cerebrospinal fluid. $\mathcal{F}$ Neurol Neurosur Psychiatry 1981;44:329-33.

22 Day JW, Raskin NH. Thunderclap headache; symptom of unruptured cerebral aneurysm. Lancet 1986;ii:1247-8.

3 Anonymous. Headaches and subarachnoid haemorrhage [Editorial]. Lancet 1988;ii:80-2.

24 Raps EC, Rogers JD, Galetta SL, Solomon RA, Lennihan Raps EC, Rogers JD, Galetta SL, Solomon RA, Lennihan
L, Klebanoff LM, et al. The clinical spectrum of unrupL, Klebanoff LM, et al. The clinical spectrum of unrup-
tured intracranial aneurysms. Arch Neurol 1993;50: 265-9. 